\title{
0152 STRESS IN A WORKPLACE IN MONGOLIA
}

B Baasanjargal*, G Otgon, T S Lkhagvasyren Correspondence: Health Sciences University of Mongolia, PO Box-48/111, Ulaanbaatar, 210648, Mongolia

10.1136/ip.2010.029215.152

The aim of study is to increase the labour ability by determining immune system changes and estimating stress level of the workers on their jobs.

1000 people including shop assistants, health personnel, policemen and lawyers were involved in the questionnaire and level of stress was defined by the test and questionnaire of Teilor. It was defined that $21 \%$ of them had no stress, and $78 \%$ had stress; $47.6 \%$ with first degree, $18.1 \%$ with second degree, $13.2 \%$ with third degree.

70 people with the second and third level of stress in the case group and 20 people with the 0 level stress in control group were chosen for immune test.

After comparing the amount of cortisol in the blood serum of people in case and control groups, the cortisol level of people with stress has increased $(p<0.0001)$ than the people who had no stress.

It shows that interleukin 6 (IL- 6$)(p<0.01)$, tumour necrosis factor (TNF) $(p<0.05)$ in the blood serum of people with stress has increased than the people in the control group.

It can be concluded that $78.9 \%$ of workers in hospital, legal and commercial organisations feel stress in their workplaces.

The amount of cortisol in blood serum have been increased during stress.

Cytokine in the blood serum can lead to change the function of the immune system of the body. $\alpha$ Increase of IL- 6 , TNF. 